\title{
Activation of Skeletal Muscle Casein Kinase II by Insulin is not Diminished in Subjects with Insulin Resistance
}

Ryo Maeda, Itamar Raz, Francesco Zurlo, and James Sommercorn

Clinical Diabetes and Nutrition Section, National Institute of Diabetes and Digestive and Kidney Diseases, National Institutes of Health, Phoenix, Arizona 85016

\begin{abstract}
Insulin resistance, which may precede the development of noninsulin-dependent diabetes mellitus in Pima Indians, appears to result from a postreceptor defect in signal transduction in skeletal muscle. To identify the putative postreceptor lesion responsible for insulin resistance in Pima Indians, we investigated the influence of insulin on the activity of casein kinase II (CKII) in skeletal muscle of seven insulin-sensitive, four insulin-resistant, nondiabetic, and five insulin-resistant diabetic Pima Indians during a 2 h hyperinsulinemic, euglycemic clamp. In sensitive subjects, CKII was transiently activated reaching a maximum over basal activity (42\%) at $45 \mathrm{~min}$ before declining. CKII was also stimulated in resistant $(19 \%)$ and diabetic $(34 \%)$ subjects. Basal CKII activity in resistant subjects was $40 \%$ higher than in either sensitive or diabetic subjects, although the concentration of CKII protein, as determined by Western blotting, was equal among the three groups. Basal CKII activity was correlated with fasting plasma insulin concentrations, suggesting that the higher activity in resistant subjects resulted from insulin action. Extracts of muscle obtained from all three groups either before or after insulin administration were treated with immobilized alkaline phosphatase, which reduced and equalized CKII activity. These results suggest that insulin stimulates CKII activity in human skeletal muscle by a mechanism involving phosphorylation of either CKII or of an effector molecule, and support the idea that elevated basal activity in resistant subjects results from insulin action. It appears that the ability of insulin to activate CKII in skeletal muscle is not impaired in insulin-resistant Pima Indians, and that the biochemical lesion responsible for insulin resistance occurs either downstream from CKII or in a different pathway of insulin action. (J. Clin. Invest. 1991. 87:1017-1022.) Key words: insulin signal transduction • protein phosphorylation • protein kinase
\end{abstract}

\section{Introduction}

The Pima Indians have the highest known prevalence of noninsulin-dependent diabetes mellitus (NIDDM), ${ }^{1}$ a disease that

This work has appeared in abstract form (1990. Diabetes 39(Suppl): 146.

Address correspondence and reprint requests to Dr. James Sommercorn, Clinical Diabetes \& Nutrition Section, National Institutes of Health, 4212 North 16th Street, Room 541, Phoenix, AZ 85016. 1990

Received for publication 18 July 1990 and in revised form 9 October

1. Abbreviations used in this paper: CKII, casein kinase II; EGF, epidermal growth factor; IGF-1, insulin-like growth factor 1; NIDDM, noninsulin-dependent diabetes mellitus; $\mathrm{PP}_{1}-\mathrm{I}$, the form of type I phosphatase comprising a catalytic subunit and inhibitor 2 .

The Journal of Clinical Investigation, Inc.

Volume 87, March 1991, 1017-1022 may be inherited as a single autosomal gene (1). Longitudinal studies have demonstrated that subjects with normal glucose tolerance, who subsequently develop NIDDM, first develop impaired glucose tolerance, a condition that is characterized by a reduced capacity of skeletal muscle to respond to circulating insulin (2). Insulin-resistant subjects were found to have lower rates of insulin-stimulated, nonoxidative glucose disposal (glycogen synthesis) in skeletal muscle than did insulin-sensitive subjects (3), a difference that can be explained by abnormal activation of glycogen synthase in response to insulin in these subjects (4). Because insulin resistance may be an expression of the genetic lesion ultimately responsible for NIDDM, an understanding of its biochemical and molecular basis is critical for understanding the cause and potential treatment of the disease.

Insulin resistance results from a failure in the mechanism of insulin signal transduction. Although this mechanism is not entirely understood, it is known that reversible protein phosphorylation is involved. The $\beta$-subunit of the insulin receptor is a ligand-activated tyrosine protein kinase (5-7). The hormone promotes phosphorylation of several proteins on tyrosine and alters the contents of phosphoserine and phosphothreonine in other proteins (8). These latter effects result from changes in activities of a variety of serine/threonine-specific protein kinases (reviewed in reference 9) and phosphatases (10-12) in response to insulin. Studies of insulin binding and stimulation of the insulin receptor tyrosine protein kinase in skeletal muscle have not revealed abnormalities that could account for insulin resistance in the Pima Indians (13). Because the insulin receptor cDNAs from insulin-resistant Pima Indians predict normal protein sequences $(14,15)$, the defect in insulin signal transduction that accounts for insulin resistance appears to occur after the receptor.

This postreceptor lesion affects the activation by insulin of both glycogen synthase (4) and glycogen synthase phosphatase (12) in skeletal muscle. Because glycogen synthase is activated by dephosphorylation, it is likely that the defective activation of the phosphatase accounts for the abnormal response of glycogen synthase. Thus, the defect in the pathway of insulin signal transduction is either in the structure of the phosphatase itself or in elements leading to the activation of the phosphatase. The insulin-stimulated glycogen synthase phosphatase in human skeletal muscle is a type 1 enzyme (unpublished observations). One form of this phosphatase, $P_{P_{1}}-\mathrm{I}$, is a complex comprising a catalytic subunit and an inhibitor protein, inhibitor-2 (16). $\mathrm{PP}_{1}-\mathrm{I}$ is activated upon phosphorylation of inhibitor- 2 by glycogen synthase kinase 3 , a reaction that is enhanced by prior phosphorylation of inhibitor- 2 by casein kinase II (CKII) (17), an enzyme that in cultured cells is activated in response to insulin $(18,19)$ and other peptide growth factors (18-20) and to serum (21). Studies using isolated adipocytes suggest that phosphorylation of the CKII site in inhibitor-2 is enhanced in response to insulin (22). Thus, CKII may be in- 


\begin{tabular}{|c|c|c|c|c|c|c|c|}
\hline \multirow[b]{2}{*}{ Group } & \multirow[b]{2}{*}{ Age } & \multirow[b]{2}{*}{ Height } & \multirow[b]{2}{*}{ Body weight } & \multirow[b]{2}{*}{ Body mass index } & \multirow[b]{2}{*}{ Fat } & \multicolumn{2}{|c|}{ OGTT* results } \\
\hline & & & & & & FPG & $2 \mathrm{~h} \mathrm{PG}$ \\
\hline & $y r$ & $\mathrm{~cm}$ & $k g$ & $\mathrm{~kg} / \mathrm{m}^{2}$ & $\%$ & \multicolumn{2}{|c|}{$m g / d l$} \\
\hline Sensitive & $26.7 \pm 1.4$ & $167.2 \pm 1.8$ & $81.0 \pm 8.4$ & $28.9 \pm 2.9$ & $23 \pm 4$ & $92 \pm 4$ & $111 \pm 7$ \\
\hline Resistant & $39.2 \pm 2.7^{\ddagger}$ & $170.0 \pm 3.6$ & $129.6 \pm 9.3^{\ddagger}$ & $45.0 \pm 3.3^{8}$ & $41 \pm 3^{\S}$ & $110 \pm 2^{\S}$ & $179 \pm 15^{t}$ \\
\hline Diabetic & $26.4 \pm 2.0$ & $170.8 \pm 2.2$ & $103.2 \pm 16.0$ & $35.1 \pm 5.0$ & $31 \pm 5$ & $232 \pm 17^{\ddagger}$ & $373 \pm 22^{t}$ \\
\hline
\end{tabular}

* Oral glucose tolerance test; FPG, fasting plasma glucose; PG, plasma glucose. ${ }^{\S} P<0.05$ compared with sensitive; ${ }^{\ddagger} P<0.01$ compared with sensitive.

strumental in the mechanism of activation of type 1 phosphatase by insulin. Accordingly, we have examined the influence of insulin on CKII activity in human skeletal muscle to determine if an abnormal response in insulin-resistant subjects might contribute to the mechanism of insulin resistance.

\section{Methods}

Subjects. 16 Pima Indians (14 males and 2 females) were admitted to the Clinical Diabetes and Nutrition Section, National Institute of Diabetes and Digestive and Kidney Diseases, National Institute of Health. After written informed consent was obtained, subjects were given physical examinations including a 12-lead electrocardiogram. After an overnight fast, routine blood chemical and hematological examinations were performed. All subjects had normal physical examinations, electrocardiograms, and blood tests and none was taking medications. Each subject underwent a 75-g oral glucose tolerance test after receiving a diet containing $200 \mathrm{~g}$ carbohydrate for at least $2 \mathrm{~d}$. Based on the rate of glucose disposal during a hyperinsulinemic euglycemic clamp and on criteria established by the National Diabetes Data Group (23), the subjects were categorized as insulin-sensitive ( $n=7$; M value (glucose disposal rate) $\geq 8 \mathrm{mg} / \mathrm{min} \cdot \mathrm{kg}$ fat-free mass), insulin-resistant, nondiabetic $(n=4 ; \mathrm{M} \leq 8)$, and insulin-resistant diabetic $(n=5 ; \mathrm{M}$ $\leq 8$ ). Body fat was estimated by underwater weighing with simultaneous measurement of residual lung volume (24). The characteristics of the patients and results of oral glucose tolerance tests are summarized in Table I.

Hyperinsulinemic euglycemic clamp and muscle biopsy. After an overnight fast, the euglycemic clamp was initiated by a primed continuous high dose insulin infusion $\left(600 \mathrm{mU} / \mathrm{min}\right.$ per $\left.\mathrm{m}^{2}\right)$ for $120 \mathrm{~min}$ as previously described (25). The plasma insulin concentration was measured by automated radioimmunoassay (Concept 4: ICN Pharmaceuticals, Inc., Horsham, PA) before the start of the insulin infusion and at $12.5,27.5,55$, and 90 min during the clamp. $M$ value was determined during the last $40 \mathrm{~min}$ of the clamp.

Percutaneous muscle biopsies were taken from quadriceps femoris before and at 15, 30, 45, 60, and $90 \mathrm{~min}$ after the start of insulin infusion. After local anesthesia of skin and muscle fascia, incisions were made at intervals of at least $2 \mathrm{~cm}, 1-2$ inches from the midline of both midlateral thighs. The muscle specimens were collected using a Bergström needle and frozen in liquid nitrogen within $5 \mathrm{~s}$ and subsequently stored at $-70^{\circ} \mathrm{C}$. Glucose disposal rates and concentrations of glucose and insulin in plasma before and at steady states during the clamp are summarized in Table II.

Preparation of muscle extracts. Frozen biopsy specimens were lyophilized, dissected free of blood, fat, and connective tissue, and then powdered using a mortar and pestle. Powdered muscle was mixed with buffer comprising $80 \mathrm{mM} \beta$-glycerophosphate, $20 \mathrm{mM}$ EGTA, $15 \mathrm{mM}$ $\mathrm{MgCl}_{2}, \mathrm{pH} 7.3$, at a ratio of $0.25 \mathrm{ml} / \mathrm{mg}$ and disrupted at $4^{\circ} \mathrm{C}$ for $20 \mathrm{~s}$ using an OMNI 1000 homogenizer (OMNI International, Inc., Waterbury, CT) at high speed. The homogenate was centrifuged at $100,000 \mathrm{~g}$ for $30 \mathrm{~min}$ at $4^{\circ} \mathrm{C}$ and the supernatant fraction was stored at $-70^{\circ} \mathrm{C}$.

Casein kinase II assay. CKII activity was assayed using a peptide with the sequence Arg-Arg-Arg-Glu-Glu-Glu-Thr-Glu-Glu-Glu that is a specific substrate for CKII (26) and that is useful for measuring CKII activity in extracts of cells (27). Aliquots of muscle extract $(12 \mu \mathrm{l})$ were incubated in a final volume of $30 \mu \mathrm{l}$ at $30^{\circ} \mathrm{C}$ for $20 \mathrm{~min}$ in the presence of $50 \mathrm{mM}$ Tris- $\mathrm{HCl}, \mathrm{pH} 7.6,10 \mathrm{mM} \mathrm{MgCl}, 100 \mu \mathrm{M}\left[\gamma-{ }^{32} \mathrm{P}\right] \mathrm{ATP}$ $(1,500-4,000 \mathrm{cpm} / \mathrm{pmol})$ with or without $2 \mathrm{mM}$ peptide in duplicate. Reactions were started by adding ATP and were stopped by applying $25 \mu \mathrm{l}$ of the reaction mixtures on Whatman P-81 papers (Whatman Inc., Clifton, NJ), which were then washed five times with $10 \mathrm{mM}$ $\mathrm{H}_{3} \mathrm{PO}_{4}$ and once with $95 \%$ ethanol and dried. Radioactivity associated with the papers was determined by liquid scintillation spectrometry. The ratio of radioactivity incorporated in the presence of peptide substrate divided by radioactivity incorporated in its absence was $4.5 \pm 0.15$ (mean \pm SE; $n=18$ ). Kinase activity was calculated on the basis of net phosphorylation of peptide. Assays were linear with both the amount of muscle extract (5-15 $\mu \mathrm{g}$ protein/assay) and with time up to $30 \mathrm{~min}$ (data not shown).

Alkaline phosphatase treatment. Before treatment with alkaline phosphatase, aliquots of muscle extracts $(240 \mu \mathrm{l})$ were concentrated to $60 \mu 1$ using Bio-Rad Ultracent-30 concentrators (Bio-Rad Laboratories, Richmond, CA) and then diluted in $600 \mu \mathrm{l}$ of buffer A (15 mM

Table II. Glucose Disposal Rates and Concentrations of Plasma Glucose and Insulin during the Clamp

\begin{tabular}{|c|c|c|c|c|c|}
\hline \multirow[b]{2}{*}{ Group } & \multicolumn{2}{|c|}{ Before the start of clamp } & \multicolumn{2}{|c|}{ At steady state of clamp } & \multirow[b]{2}{*}{ Glucose disposal rate } \\
\hline & Glucose & Insulin & Glucose & Insulin & \\
\hline & $m g / d l$ & $\mu U / m l$ & $m g / d l$ & $\mu U / m l$ & $\mathrm{mg} / \mathrm{min} \cdot \mathrm{kg}-\mathrm{FFM}$ \\
\hline Sensitive & $101 \pm 4$ & $9.1 \pm 2.0$ & $93 \pm 2$ & $2382 \pm 162$ & $10.3 \pm 0.7$ \\
\hline Resistant & $131 \pm 5$ & $41.3 \pm 6.0^{\ddagger}$ & $98 \pm 2$ & $2845 \pm 123$ & $4.4 \pm 0.7^{*}$ \\
\hline Diabetic & $227 \pm 19^{\ddagger}$ & $20.6 \pm 8.6$ & $115 \pm 9 *$ & $2310 \pm 170$ & $4.6 \pm 0.5^{\ddagger}$ \\
\hline
\end{tabular}

FFM, fat-free mass. ${ }^{*} P<0.05$ compared with sensitive; ${ }^{\ddagger} P<0.01$ compared with sensitive. 
Tris- $\mathrm{HCl}$, pH 7.9, $5 \mathrm{mM} \mathrm{KCl}, 0.5 \mathrm{mM} \mathrm{MgCl} 2,0.5 \mathrm{mM}$ dithiothreitol, and $1 \mathrm{mM}$ phenylmethylsulfonyl fluoride) (20). The diluted extracts were again concentrated to $60 \mu \mathrm{l}$ and diluted with $600 \mu \mathrm{l}$ of buffer A before being concentrated to $\sim 100 \mu \mathrm{l}$. Two equal aliquots of each resultant extract in buffer A were incubated in a total volume of $120 \mu \mathrm{l}$ with or without $1 \mathrm{U}$ of alkaline phosphatase (equilibrated in buffer $\mathrm{A}$ ), in the presence of $100 \mu \mathrm{M} \mathrm{ZnCl}_{2}$ at $23^{\circ}$ for $15 \mathrm{~min}$ (20). Alkaline phosphatase beads were then sedimented by centrifugation and CKII activity in the supernatant fraction and in the reaction mix without phosphatase was assayed as described above. For control reactions, alkaline phosphatase beads were boiled for $20 \mathrm{~min}$, which inactivated the enzyme assayed with $p$-nitrophenylphosphate as a substrate.

Western blotting. Aliquots of muscle extracts that each contained $25 \mu \mathrm{g}$ of protein were subjected to SDS-PAGE on a $12.5 \%$ gel. Proteins were transferred from the gel to nitrocellulose using a Bio-Rad Laboratories blotting apparatus at $60 \mathrm{~V}$ for $4 \mathrm{~h}$ in a cold room. The nitrocellulose blot was developed with antiserum to bovine thymus CKII and ${ }^{125}$ I-protein A as described previously (27). After autoradiography, the bands corresponding to the $\alpha$ - and $\beta$-subunits of CKII were cut out, and associated radioactivity in each was determined by $\gamma$-counting. The radioactivity associated with both subunits was linear with the amount of extract protein up to $50 \mu \mathrm{g}$ (data not shown).

Materials. $\left[\gamma-{ }^{32} \mathrm{P}\right] \mathrm{ATP}$ and ${ }^{125} \mathrm{I}$-protein A were purchased from New England Nuclear, Boston, MA. Antiserum to bovine thymus CKII was obtained from Dr. Michael Dahmus, University of California, Davis, CA. The peptide with the sequence Arg-Arg-Arg-Glu-GluGlu-Thr-Glu-Glu-Glu was obtained from Peninsula Laboratories, Inc., Belmont, CA. Immobilized alkaline phosphatase was purchased from Sigma Chemical Co., St. Louis, MO.

Statistical analysis. The data presented are mean values \pm 1 SE of the mean. Comparisons of two sample means were made using Student's $t$ test. Statistical significance of the effect of insulin on CKII activity during the insulin infusion (Fig. 1) was assessed by repeated measures analysis of variance.

\section{Results}

Time course of insulin-stimulated casein kinase II activity. Fig. 1 shows the effect of insulin on CKII activity measured in ex-

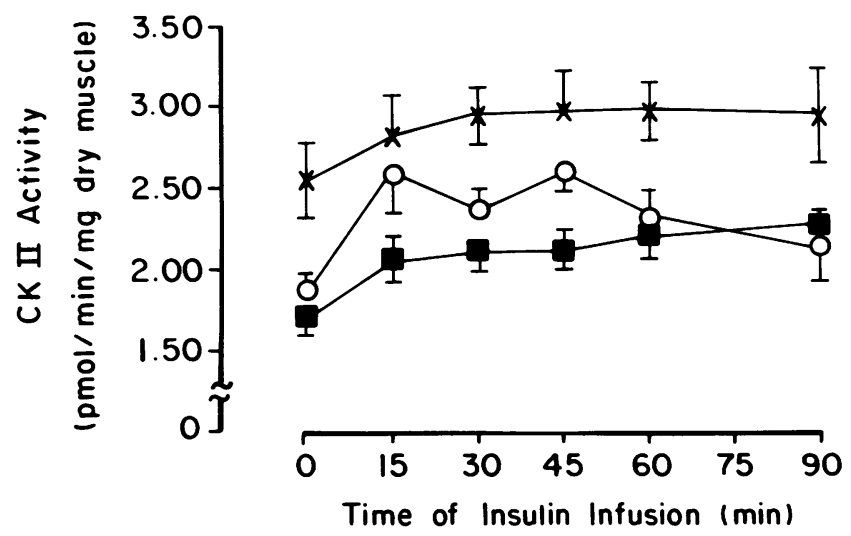

Figure 1. Activation of casein kinase II by insulin in human skeletal muscle. Muscle biopsies were taken before and at various times during a hyperinsulinemic, euglycemic clamp. The preparation of muscle extracts and assays of CKII activity are described in Methods. The data are means \pm SEM for seven insulin-sensitive (o), four insulin-resistant, nondiabetic $(\times)$, and five insulin-resistant diabetic ( $($ ) subjects. The effect of insulin on CKII activity in all three groups was significant $(P<0.05)$ as assessed by repeated measures analysis of variance. Basal CKII activity $(t=0)$ in resistant subjects was significantly higher $(P<0.05)$ than in sensitive or diabetic subjects as assessed by Student's $t$ test. tracts of human skeletal muscle obtained during a high dose insulin clamp. In sensitive subjects, CKII activity was rapidly and transiently stimulated. The effect was essentially maximal ( $37 \pm 8 \%$ over basal) by $15 \mathrm{~min}$ and persisted through $45 \mathrm{~min}$ ( $42 \pm 11 \%$ over basal) after which activity began to decline. The activation was biphasic in three subjects, which accounts for the slightly lower activity at $30 \mathrm{~min}$ than at 15 and $45 \mathrm{~min}$. CKII activity was also increased in response to insulin in diabetics, however, in contrast to sensitive subjects, the activity remained elevated over the 90 -min period examined. The maximum activation ( $34 \pm 7 \%$ over basal) was similar to that seen in sensitive subjects, but it was not achieved until $90 \mathrm{~min}$. The time course of the response of CKII to insulin in nondiabetic resistant subjects was similar to that in the diabetics, but the magnitude of activation $(19 \pm 10 \%)$ was only about one-half that achieved in the other groups. The magnitude of the insulin effect in resistant subjects may be limited because of a higher basal CKII activity and a limit to the maximum obtainable specific activity, which under our experimental conditions appears to be about $3 \mathrm{pmol} / \mathrm{min}$ per $\mathrm{mg}$ dry muscle.

Basal CKII activity. To determine whether differences in basal CKII activity among the three groups could be explained by different concentrations of CKII, three extracts from each group were subjected to immunoblot analysis and quantitation of both $\alpha$ - and $\beta$-subunits of CKII. Fig. 2 shows an autoradiogram of the immunoblot. It is apparent from inspection that the concentration of CKII is similar among the three groups. An additional aliquot of one sample (number 3 ) from each group that contained twice the amount of extract protein was analyzed to demonstrate that the blotting technique can detect small differences in CKII protein (see also reference 18). Bands corresponding to $\alpha$ - and $\beta$-subunits of CKII were excised and associated radioactivity was determined by $\gamma$-counting. CKII activity was not correlated with the amount of either $\alpha$-subunit $(r=-0.21)$ or $\beta$-subunit $(r=-0.19)$, indicating that the higher basal CKII activity in resistant subjects does not result from overexpression of CKII, but rather from elevated activity of the enzyme. Because insulin-resistant nondiabetic subjects were hyperinsulinemic, it is possible that the elevated basal CKII activity is the result of insulin action. This possibility is sup-

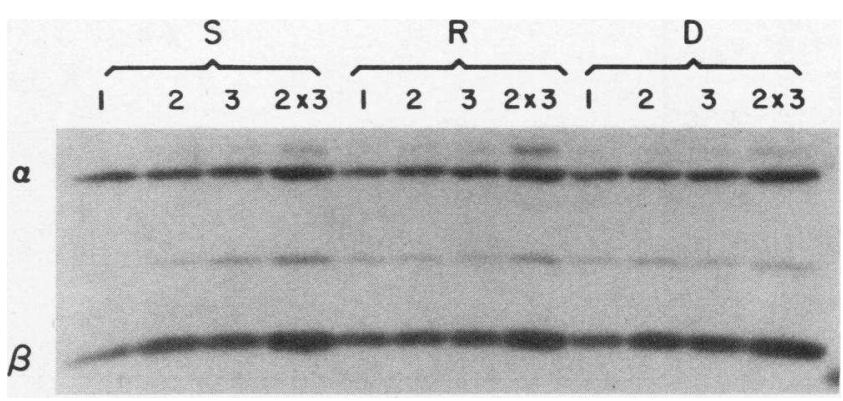

Figure 2. Immunoblot analysis of casein kinase II in extracts of human skeletal muscle. Aliquots of extracts that each contained 25 $\mu \mathrm{g}$ of total protein were subjected to SDS-PAGE and electrophoretic transfer to nitrocellulose. The blots were developed with CKII antibody and ${ }^{125} \mathrm{I}$-protein $\mathrm{A}$ and an autoradiogram was prepared as described previously (27). S1-S3 refer to samples from insulin sensitive subjects, R1-R3 from resistant, nondiabetics, and D1-D3 are samples from resistant diabetic subjects. Lanes labeled $2 \times 3$ contained $50 \mu \mathrm{g}$ of protein from extracts of sensitive, resistant, and diabetic subjects. 
ported by the data in Fig. 3, which shows that among all subjects, basal CKII activity was correlated with fasting plasma insulin levels $(r=0.61 ; P<0.02)$.

Mechanism of insulin-stimulated casein kinase II. The mechanism by which insulin activates CKII is not known. Previous studies have shown that insulin-stimulated CKII activity is stable to gel filtration (18) or ion-exchange chromatography (19), suggesting that the kinase is covalently modified in response to insulin. Ackerman et al. (20) provided evidence that the mechanism by which epidermal growth factor stimulates CKII involves phosphorylation of the enzyme or of an effector protein. Treatment of extracts from EGF-stimulated cells with immobilized alkaline phosphatase restored CKII activity to control levels. Subsequent studies have shown that EGF promotes phosphorylation of the $\beta$-subunit of CKII and that enzyme activity is tightly associated with the extent of its phosphorylation (28). To determine if insulin activates CKII by a mechanism similar to that of EGF, we treated extracts of muscle, taken from all three groups before and after insulin administration, with immobilized alkaline phosphatase. Fig. 4 shows that treatment with alkaline phosphatase reduced and equalized CKII activity among the extracts. To verify that this effect was the result of phosphatase activity, control incubations were done using phosphatase that was inactivated by heating at $100^{\circ} \mathrm{C}$, which eliminated the ability of the alkaline phosphatase to reduce CKII activity in the extracts (Table III). Thus, in all three groups, the mechanism by which insulin stimulates CKII activity appears to involve phosphorylation of the enzyme or of an effector molecule. Furthermore, because phosphatase treatment equalized basal CKII activities, the higher basal activity of CKII in resistant subjects compared with the other groups apparently can be accounted for by a similar phosphorylation mechanism. This result lends further support to the interpretation that higher basal CKII activity is caused by the higher fasting insulin levels in resistant subjects.

\section{Discussion}

Studies of the mechanism of insulin-resistance in skeletal muscle of Pima Indians have identified target enzymes and several

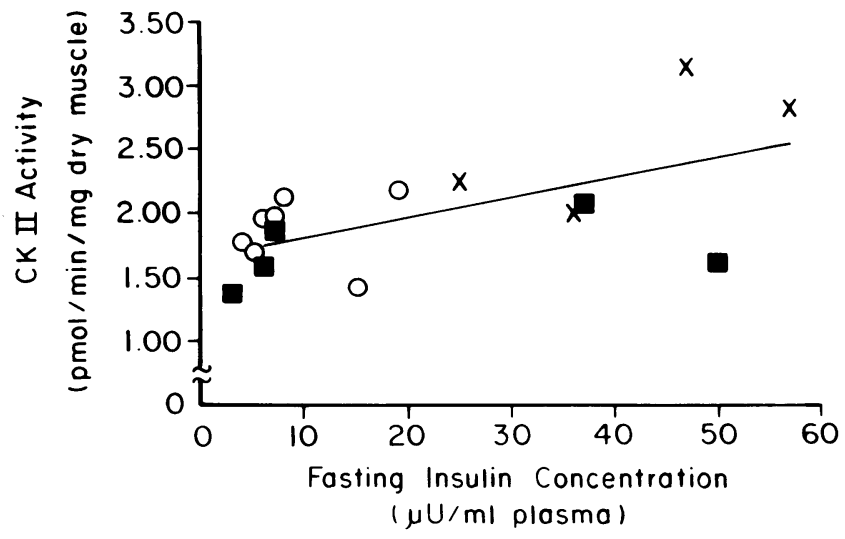

Figure 3. Relationship between basal casein kinase II activity and the concentration of insulin in plasma of fasting subjects. The preparation of extracts and assays of CKII and insulin are described in Methods. Subjects were either insulin sensitive (O), insulin-resistant, nondiabetic $(\times)$, or insulin-resistant diabetic ( $\bullet$ ). CKII activity was positively correlated with the concentration of insulin in plasma $(r$ $=0.61 ; P<0.02$ ).

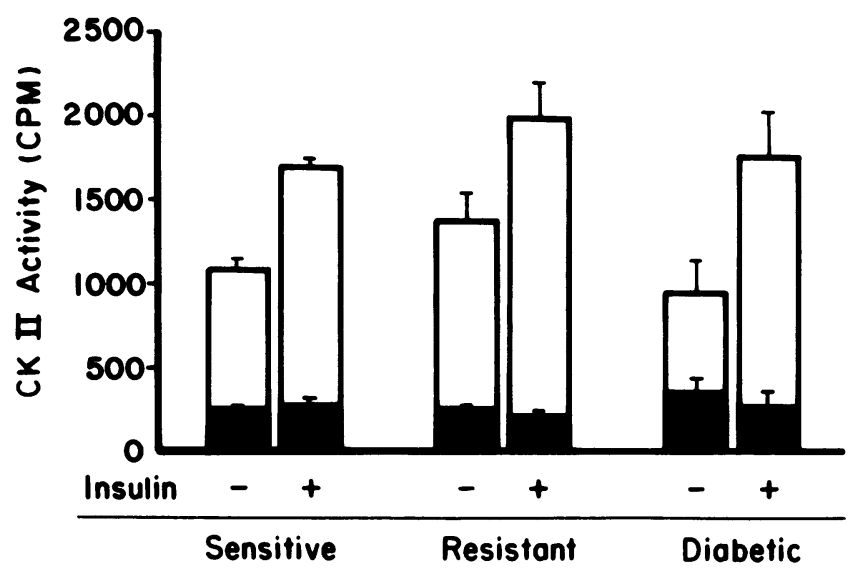

Figure 4. Effect of alkaline phosphatase on casein kinase II activity in extracts of muscle obtained before and after insulin administration. Extracts were prepared from muscle of insulin-sensitive, insulin-resistant, nondiabetic and insulin-resistant diabetic subjects either before ( -$)$ or after $(+)$ administration of insulin. Extracts were assayed for CKII activity before (open bars) and after treatment with immobilized alkaline phosphatase (solid bars) as described in Methods. Data are mean $\pm \operatorname{SEM}(n=3)$.

potential elements of the insulin signal transduction pathway that are affected. Glycogen synthase (4), glycogen synthase phosphatase (12), phosphorylase phosphatase (unpublished observations), and S6 Kinase (29) all respond more slowly and to a lesser extent than is normal. However, one critical element of the pathway, the insulin receptor, does not appear to be affected in such a way as to contribute to insulin resistance (13). Thus, the biochemical defect in insulin signal transduction appears to lie between the receptor and various downstream elements of the pathway(s) of insulin action. The simplest interpretation of the results of our studies is that the ability of insulin to activate CKII is not impaired in insulin-resistant nondiabetic subjects. Results presented in Fig. 1-3 suggest that, in the basal fasting state, CKII in muscle of resistant nondiabetics is already activated by insulin to a level greater than that in sensitive subjects. This may result from both the higher fasting insulin concentrations in resistant nondiabetic subjects (Table II and Fig. 3) as well as the fact that the insulin receptor in skeletal muscle of resistant nondiabetic subjects is more sensitive to insulin than is the receptor from sensitive subjects (13). In addition to the activation by endogenous insulin, CKII activ-

Table III. Effect of Heat Inactivation on the Ability of Alkaline Phosphatase to Reduce Casein Kinase II Activity in Muscle Extracts

\begin{tabular}{lcc}
\hline & \multicolumn{2}{c}{ CKII Activity (\% of control) } \\
\hline Control & 100 & \\
Alkaline phosphatase & $27.9 \pm 5.2$ & $P<0.0001$ \\
Heated alkaline phosphatase & $91.5 \pm 6.7$ & NS
\end{tabular}

10 muscle extracts were incubated for $15 \mathrm{~min}$ at room temperature in the presence of $100 \mu \mathrm{M} \mathrm{ZnCl}_{2}$ with either $1 \mathrm{U}$ of alkaline phosphatase or with the equivalent amount of heat-inactivated alkaline phosphatase or with neither (Control). After centrifugation, supernatant fractions were assayed for CKII activity as described in Methods. Data are means \pm SEM. 
ity in muscles of resistant subjects is increased even further in response to infused insulin during the clamp, and at all time points, CKII activity in resistant subjects is higher than it is in muscle of insulin-sensitive subjects. Thus, CKII apparently participates in insulin signal transduction either before the lesion responsible for insulin resistance or in a separate pathway of insulin action that is not affected by the lesion. Evidence that insulin signal transduction may involve more than one pathway has been obtained from studies using either antibodies to the normal insulin receptor (30) or mutated receptors transfected into normal cells $(31,32)$. In these studies, manipulation of the receptor impairs some aspects of insulin action but not others. In particular, it appears that insulin may affect nuclear events, such as stimulation of mitosis and possibly gene transcription, by means other than those by which it influences metabolic pathways.

The lower magnitude of increase in CKII activity in response to infused insulin in resistant subjects likely results from the fact that much of the potential activation has been realized before the start of the insulin infusion. This may also account for the slower rise of CKII activity in response to infused insulin in these subjects than in sensitive subjects. The response of CKII to insulin in resistant subjects is likely an approach to a plateau, whereas in sensitive subjects, in which CKII activity starts lower, the response may reflect an initial rate of activation.

The response of CKII to infused insulin appears to be abnormal in muscles of insulin-resistant diabetic subjects (Fig. 1). The response is slower and at all but the 90 -min timepoint, CKII activity is lower than it is in muscles of insulin-sensitive subjects. However, the magnitude of the increase, expressed as a fractional increase over basal activity, was similar in the diabetics and normals ( 34 vs. $42 \%$ ). It is possible that the slower response of CKII in diabetics results from hormonal or metabolic responses that are secondary to the development of diabetes. The response of CKII to infused insulin in resistant and diabetic subjects differs from that in sensitive subjects in that it is not a transient activation over the 90 -min period studied. Because the stimulation of CKII activity that occurs in response to insulin is counteracted by the action of a phosphatase (Fig. 4), it is possible that the decline of CKII activity in sensitive subjects that occurs between 45 and $90 \mathrm{~min}$ of insulin infusion involves dephosphorylation of CKII or of an effector protein. The fact that CKII activity in both resistant and diabetic subjects does not decline after stimulation by insulin, may reflect the abnormally low activation of protein serine/ threonine phosphatase activity by insulin in these subjects (12). The lack of phosphatase stimulation also may allow CKII to achieve a higher maximum activity in resistant subjects than in sensitive subjects. Although the overall response of CKII to insulin is different between resistant and sensitive subjects, the difference probably does not result from a defect in getting the signal to CKII to activate it, but rather from a defect in the ability to activate a phosphatase, which could attenuate CKII activation. Because the activation of CKII does not appear to be impaired by insulin resistance, the basis of abnormal activation of type I protein phosphatase probably involves other mechanisms that influence its activity. These may include glycogen synthase kinase 3 (17), cAMP-dependent protein kinase acting through inhibitor 1 , or the interaction of the catalytic subunit of the phosphatase with a variety of targeting subunits (33).
The magnitude of activation of CKII in muscle of insulinsensitive subjects in response to infused insulin was $\sim 40 \%$ over basal activity, which is consistent with results of our earlier studies using 3T3-L1 cells and H4-IIE hepatoma cells (18). This is a relatively modest activation compared with the twoto tenfold stimulations of CKII in response to insulin, IGF-1, EGF, and serum that have been reported (19-21). The magnitude of response depends of course on the activity of the enzyme in the basal state. We found that alkaline phosphatase treatment suppressed basal CKII activity in extracts of human skeletal muscle by $75 \%$ (Fig. 4). Thus, it appears that in the basal state, CKII activity is already substantially influenced by means involving the same mechanism by which it is activated in response to insulin. This fact probably restricts the magnitude of response of CKII to hormonal treatment. If one considers the CKII activity after phosphatase treatment as a theoretical basal activity, then the potential range of response of CKII to insulin in human muscle is about six- to ninefold. In contrast to our findings, Ackerman and Osheroff found no effect of alkaline phosphatase on CKII activity measured in extracts of hormone-naive A431 cells, suggesting that their protocol for handling cells before exposure to epidermal growth factor was effective in suppressing basal CKII activity to a minimum. These cells likely had a much greater potential for CKII activation, which achieved fivefold over basal activity in response to EGF (20). Thus, the magnitude of CKII activation in response to a hormone may be more a function of the basal activity than it is of the maximum activity achieved in response to the hormone. Differences in basal CKII activity may account for the considerable variation in the magnitude of response of the kinase to various hormones or growth factors that have been reported.

\section{Acknowledgments}

We are grateful to Carol Lamkin and the Nursing Staff for their care of the subjects and for assistance in performing clinical procedures, to Rose Fields for technical assistance, to Dr. Michael Dahmus for providing antibody to CKII, to Charlesetta Lincoln for preparing the typescript, and to the individuals who volunteered for these studies.

\section{References}

1. Yamashita, T., W. Nejak, N. B. Rushforth, P. H. Bennett, and H. Houser. 1984. Pedigree analysis of noninsulin-dependent diabetes mellitus in the Pima Indians suggests dominant mode of inheritance. Am. J. Hum. Genet. 36:1835.

2. Bogardus, C. 1989. Perspective: does insulin resistance primarily affect skeletal muscle? Diab/Metab. Rev. 5:567-568.

3. Lillioja, S., D. M. Mott, J. K. Zawadzki, A. A. Young, W. G. Abbott, and C. Bogardus. 1986. Glucose storage is a major determinant of in vivo "insulin resistance" in subjects with normal glucose tolerance. J. Clin. Endocrinol. Metab. 5:922-927.

4. Freymond, D., C. Bogardus, M. Okubo, K. Stone, and D. Mott. 1988. Impaired insulin-stimulated muscle glycogen synthase activation in vivo in man is related to low fasting glycogen synthase phosphatase activity. J. Clin. Invest. 82:1503-1509.

5. Zick, Y., J. Whittaker, and J. Roth. 1983. Insulin stimulated phosphorylation of its own receptor: activation of a tyrosine-specific protein kinase that is tightly associated with the receptor. J. Biol. Chem. 258:3431-3434.

6. Kasuga, M., Y. Fujita-Yamaguchi, D. L. Blithe, and C. R. Kahn. 1983. Tyrosine-specific protein kinase activity is associated with the purified insulin receptor. Proc. Natl. Acad. Sci. USA. 80:2137-2141.

7. Petruzzelli, L., R. Herrera, and O. M. Rosen. 1984. Insulin receptor is an insulin-dependent tyrosine protein kinase: copurification of insulin-binding activity and protein kinase activity to homogeneity from human placenta. Proc. Natl. Acad. Sci. USA. 81:3327-3331.

8. Denton, R. M. 1986. Early events in insulin action. Cyclic Nucleotide Protein Phosphorylation Res. 20:293-341. 
9. Czech, M. P., J. K. Klarlund, K. A. Yagaloff, A. P. Bradford, and R. E. Lewis. 1988. Insulin receptor signaling: activation of multiple serine kinases. $J$. Biol. Chem. 263:11017-11020.

10. Lopez-Alarcon, L., M. Mojena, L. Monge, and J. E. Feliu. 1986. Stimulation of pyruvate kinase phosphatase activity by insulin in isolated rat hepatocytes. Biochem. Biophys. Res. Commun. 134:292-298.

11. Chan, C. P., S. J. McNall, E. G. Krebs, and E. H. Fisher. 1988. Stimulation of protein phosphatase activity by insulin and growth factors in 3T3 cells. Proc Natl. Acad. Sci. USA. 85:6257-6261.

12. Kida, Y., A. Esposito-Del Puente, C. Bogardus, and D. M. Mott. 1990. Insulin resistance is associated with reduced fasting and insulin-stimulated glycogen synthase phosphatase activity in human skeletal muscle. J. Clin. Invest. 85:476-481.

13. Nyomba, B. L., V. M. Ossowski, C. Bogardus, and D. M. Mott. 1990. Relationship between insulin-sensitive tyrosine kinase activity and in vivo insulin action in man. Am. J. Physiol. 258:E964-E974.

14. Cama, A., A. P. Patterson, T. Kadowaki, H. Kadowaki, G. Siegel, D. D'Ambrosio, S. Lillioja, J. Roth, and S. I. Taylor. 1990. The amino acid sequence of the insulin receptor is normal in an insulin-resistant Pima Indian. J. Clin. Endocrinol. Metab. 70:1155-1161.

15. Moller, D. E. A. Yokota, and J. S. Flier. 1989. Normal insulin-receptor cDNA sequence in Pima Indians with NIDDM. Diabetes. 38:1496-1500.

16. Cohen, P. 1989. The structure and regulation of protein phosphatases Annu. Rev. Biochem. 58:453-508.

17. DePaoli-Roach, A. A. 1984. Synergistic phosphorylation and activation of ATP-Mg-dependent phosphoprotein phosphatase by $F_{A} / G S K-3$ and casein kinase II ( $\left.\mathrm{PC}_{0.7}\right)$. J. Biol. Chem. 259:12144-12152.

18. Sommercorn, J., J. A. Mulligan, F. J. Lozeman, and E. G. Krebs. 1987 Activation of casein kinase II in response to insulin and to epidermal growth factor. Proc. Natl. Acad. Sci. USA. 84:8834-8838.

19. Klarlund, J. K., and M. P. Czech. 1985. Insulin-like growth factor I and insulin rapidly increase casein kinase II activity in BALB/c 3T3 fibroblasts. $J$. Biol. Chem. 263:15872-15875.

20. Ackerman, P., and N. Osheroff. 1989. Regulation of casein kinase II activity by epidermal growth factor in human A-431 carcinoma cells. $J$. Biol. Chem. 264:11958-11965.
21. Carroll, D., and D. R. Marshak. 1989. Serum-stimulated cell growth causes oscillations in casein kinase II activity. J. Biol. Chem. 264:7345-7348.

22. Lawrence, J. C., Jr., J. Hiken, B. Burnett, and A. A. DePaoli-Roach. 1988. Phosphorylation of phosphoprotein phosphatase inhibitor-2 (I-2) in rat fat cells. Biochem. Biophys. Res. Commun. 150:197-203.

23. National Diabetes Data Group. 1979. Classification and diagnosis of diabetes mellitus and other categories of glucose tolerance. Diabetes. 28:1039-1057.

24. Goldman, R. F., and E. R. Buskirk. 1961. A method for underwater weighing and the determination of body density. In Techniques for Measuring Body Composition. Brozek, J., Henschel, A., editors. Natl. Acad. Sci. Natl. Res. Council, Washington, DC. 78-79.

25. Bogardus, C., S. Lillioja, K. Stone, and D. Mott. 1984. Correlation between muscle glycogen synthase activity and in vivo insulin action in man. $J$. Clin. Invest. 73:1185-1190.

26. Kuenzel, E. A., and E. G. Krebs. 1985. A synthetic peptide substrate specific for casein kinase II. Proc. Natl. Acad. Sci. USA. 82:737-741.

27. Sommercorn, J., and E. G. Krebs. 1987. Induction of casein kinase II during differentiation of 3T3-L1 cells. J. Biol. Chem. 262:3839-3843.

28. Ackerman, P., C. V. C. Glover, and N. Osheroff. 1990. Stimulation of casein kinase II by epidermal growth factor: relationship between the physiological activity of the kinase and the phosphorylation state of its $\beta$-subunit. Proc. Natl. Acad. Sci. USA. 87:821-825.

29. Sommercorn, J., R. Fields, I. Raz, and R. Maeda. 1990. Abnormal activation of S6 Kinase in insulin resistance. FASEB (Fed. Am. J.) 4:2079a. (Abstr.)

30. Ponzio, G., J. O. Contreres, A. Debant, V. Baron, N. Gautier, J. DolaisKitabgi, and B. Rossi. 1988. Use of an anti-insulin receptor antibody to discriminate between metabolic and mitogenic effects of insulin: correlation with receptor autophosphorylation. EMBO (Eur. Mol. Biol. Organ.) J. 7:4111-4117.

31. Debant, A., E. Clauser, G. Ponzio, C. Filloux, C. Auzan, J. O. Contreres, and B. Rossi. 1988. Replacement of insulin receptor tyrosine residues 1162 and 1163 does not alter the mitogenic effect of the hormone. Proc. Natl. Acad. Sci. USA. 85:8032-8036.

32. Thies, R. S., A. Ullrich, and D. A. McClain. 1989. Augmented mitogenesis and impaired metabolic signaling mediated by a truncated insulin receptor. $J$. Biol. Chem. 264:12820-12825.

33. Cohen, P., and P. T. W. Cohen. 1989. Protein phosphatase come of age. J. Biol. Chem. 264:21435-21438. 